Research report

\title{
Offspring of parents with recurrent depression: Which features of parent depression index risk for offspring psychopathology?
}

\author{
Becky Mars ${ }^{\text {a,*}}$, Stephan Collishaw ${ }^{\text {a }}$, Daniel Smith ${ }^{\text {b }}$, Ajay Thapar ${ }^{\text {a }}$, Robert Potter ${ }^{\text {c }}$, Ruth Sellers ${ }^{\text {a }}$, \\ Gordon T. Harold ${ }^{d}$, Nicholas Craddock ${ }^{b}$, Frances Rice ${ }^{\mathrm{e}}$, Anita Thapar ${ }^{\mathrm{a}}$ \\ ${ }^{a}$ Child and Adolescent Psychiatry Section, Department of Psychological Medicine and Neurology, Cardiff University, MRC Centre for Neuropsychiatric Genetics \\ and Genomics, Neuroscience and Mental Health Research Institute, UK \\ ${ }^{\mathrm{b}}$ Department of Psychological Medicine and Neurology, Cardiff University, MRC Centre for Neuropsychiatric Genetics and Genomics, Neuroscience \\ and Mental Health Research Institute, UK \\ ${ }^{\mathrm{C}}$ Cwm Taf Health Board and Child and Adolescent Psychiatry Section, Department of Psychological Medicine and Neurology, Cardiff University, \\ MRC Centre for Neuropsychiatric Genetics and Genomics, Neuroscience and Mental Health Research Institute, UK \\ d School of Psychology, College of Medicine, Biological Sciences and Psychology, University of Leicester, UK \\ e Department of Clinical, Educational and Health Psychology, University College London, UK
}

\section{A R T I C L E I N F O}

Article history:

Received 29 March 2011

Received in revised form 2 September 2011

Accepted 3 September 2011

Available online 1 October 2011

Keywords:

Depression

Parental

Child

Severity

Chronicity

Timing

\begin{abstract}
A B S T R A C T
Background: Parental depression is associated with an increased risk of psychiatric disorder in offspring, although outcomes vary. At present relatively little is known about how differences in episode timing, severity, and course of recurrent depression relate to risk in children. The aim of this study was to consider the offspring of parents with recurrent depression and examine whether a recent episode of parental depression indexes risk for offspring psychopathology over and above these other parental depression features.

Methods: Three hundred and thirty seven recurrently depressed parents and their offspring (aged 9-17) were interviewed as part of an ongoing study, the 'Early Prediction of Adolescent Depression Study'. The Child and Adolescent Psychiatric Assessment was used to assess two child outcomes; presence of a DSM-IV psychiatric disorder and number of DSM-IV childrated depression symptoms.

Results: Children whose parents had experienced a recent episode of depression reported significantly more depression symptoms, and odds of child psychiatric disorder were doubled relative to children whose parents had not experienced a recent episode of depression. Past severity of parental depression was also significantly associated with child depression symptoms.

Limitations: Statistical analyses preclude causal conclusions pertaining to parental depression influences on offspring psychopathology; several features of parental depression were recalled retrospectively.

Conclusions: This study suggests that particular features of parental depression, specifically past depression severity and presence of a recent episode, may be important indicators of risk for child psychiatric disorder and depressive symptoms.
\end{abstract}

(c) 2011 Elsevier B.V. All rights reserved.

\footnotetext{
* Corresponding author at: Child and Adolescent Psychiatry Section, Department of Psychological Medicine and Neurology, Cardiff University School of Medicine, 4th Floor B-C link Corridor, Heath Park, Cardiff, CF14 4XN. Tel.:+44 29207447 91; fax: +442920743840.

E-mail addresses: marsbs1@cf.ac.uk (B. Mars), collishaws@cf.ac.uk (S. Collishaw), SmithDJ3@cf.ac.uk (D. Smith), thaparAK@cf.ac.uk (A.K. Thapar), potterr@cf.ac.uk (R. Potter), sellersr1@cf.ac.uk (R. Sellers), gth9@leicester.ac.uk (G.T. Harold), craddockn@cf.ac.uk (N. Craddock), F.rice@ucl.ac.uk (F. Rice), thapar@cf.ac.uk (A. Thapar).
}

\section{Introduction}

Parental depression is one of the strongest identified risk factors for youth psychiatric disorder, with offspring of depressed parents consistently showing heightened rates of anxiety and disruptive behaviour disorders (Weissman et al., 2006) as well as a 2-3 fold increased risk for depressive disorders when compared with controls (Rice et al., 2002). 
Levels of depressive symptoms which fall short of diagnostic criteria are also elevated in offspring of depressed parents (Connell and Goodman, 2002). Adoption and twin designs suggest that both inherited and environmental factors contribute to this increased risk for offspring psychopathology, with non-inherited factors being particularly important in the intergenerational transmission of depression (Harold et al., 2010; Silberg et al., 2010; Tully et al., 2008).

Youth depression is associated with severe adverse consequences including psychosocial impairment and an increased risk for suicide and future medical problems (Birmaher et al., 1996; Fombonne et al., 2001b; Weissman et al., 1999). Furthermore, longitudinal follow-ups of clinical and community samples demonstrate that depression occurring early in life shows strong continuity into adulthood (Fombonne et al., 2001a; Harrington et al., 1990; Pine et al., 1998; Rao et al., 1995; Rutter et al., 2006) and recurrence rates of 60 to $70 \%$ (Birmaher et al., 1996). Depressive symptoms that fall below the diagnostic threshold are also often accompanied by impairment and predict escalation to full disorder (Angold et al., 1999; Fergusson et al., 2005; Lewinsohn et al., 2000; Pickles et al., 2001; Pine et al., 1999). The long-term morbidity associated with youth depression highlights it as a serious concern for health professionals and necessitates strategies for early evidence based intervention and prevention in those children who are at greatest risk.

Despite the robust association found between parental depression and offspring psychopathology, outcomes vary with not all children going on to experience problems. There is inherent heterogeneity within the depression construct meaning that parents meeting criteria for depressive disorder will differ on clinical variables such as episode severity and chronicity, and this may go some way to explaining differences in child outcomes. This possibility is however rarely considered, with most studies comparing child outcomes according to parental diagnostic status alone (e.g. depressed compared to non-depressed).

Several longitudinal population-based studies testing links between parent depression and child psychopathology have attempted to disaggregate associations with different depression features and suggest that children of parents who have experienced a more severe, chronic course of illness are at greater risk for psychopathology than children of parents who are less seriously affected. The number, severity and duration of parental depressive episodes as well as early age of depression onset $(\leq 20)$ have all been associated with poorer child outcomes, including an increased risk for psychiatric disorder, higher levels of internalising and externalising symptoms and greater total behavioural problem scores (Brennan et al., 2000; Foster et al., 2008; Hammen and Brennan, 2003; Klein et al., 2005; Weissman et al., 1984).

Timing of parental depressive episodes may also differentially index risk in offspring. Many studies have focused on the post-natal period (with most assessing parental depression within 1 year of birth) as a time when depression exposure may be particularly harmful to children (Brand and Brennan, 2009; Murray et al., 1999, 2010, 2011). However other studies have failed to find associations with offspring depression once later maternal depressive episodes are taken into account (Halligan et al., 2007; Hay et al., 2008; Sutter-Dallay et al., 2010). These findings suggest that in addition to testing early associations between maternal depression and offspring outcomes, an important issue is how far depressive episodes occurring later in childhood and adolescence present a continuing index of risk for offspring as they grow older. This may be especially important in the transition to adolescence given that this is an important period for social and emotional development. A crucial question therefore is whether risk to older child and adolescent offspring can be usefully indexed by the presence of a recent episode of parental depression, and if so, whether this adds anything over and above risk associated with previous exposure.

The aim of the present study is to examine a group of parents with recurrent depression, and consider whether a recent episode of parental depression is associated with an increased risk of child psychopathology, over and above any risk associated with other depression characteristics such as past severity and chronicity.

\section{Methods}

\subsection{Sample}

This study utilised data from an ongoing high risk study of the offspring of recurrently depressed parents, the 'Early Prediction of Adolescent Depression' (EPAD) study. At baseline, participants included 339 parents, all of whom had a history of recurrent unipolar depression and their adolescent offspring (aged 9-17 years). The sample was recruited predominantly from general practices across South Wales (78\%). Additional participants were community volunteers recruited into the study through a database of individuals with previously identified unipolar depression (19\% who were originally identified via community mental health teams and through advertisements in local media and primary care centres) with the remainder recruited through a variety of other sources (e.g. notice boards in primary care health centres, $3 \%$, see Supplementary Fig. 1, available online).

Prior to participation in the study, parents were screened over the telephone to ensure their family fulfilled the inclusion criteria. Parents were required to have suffered from recurrent unipolar depression (at least 2 episodes; later confirmed by diagnostic interview) but need not have been experiencing a depressive episode at the time of recruitment. Additionally, parents had to be currently living with a child (age 9-17 years) to whom they were biologically related. If more than one child was present in the household and willing to participate then the youngest eligible child was selected. This served to eliminate any selection bias that may have arisen from parents suggesting the child with the greatest psychopathology for interview and also enhanced our ability to examine the development and natural history of psychopathology longitudinally, across adolescence. Parents with a psychotic or bipolar diagnosis and those who met DSM-IV criteria for mania/hypomania at the time of interview were excluded from the study. Families were also excluded if the participating child had moderate-severe intellectual disability $($ IQ $<50)$. There were no diagnostic exclusion criteria for the children at study entry. Following the baseline interview assessments, there was a final sample of 337 families who met these inclusion criteria. The adult sample consisted of 315 mothers and 22 fathers (age 26-55 years, mean 
$41.7 \mathrm{yrs}$ ) and the child sample consisted of 197 females and 140 males (age 9-17 years, mean 12.4 years). Eighty of the 337 index parents (24\%) met DSM-IV criteria for depression at baseline. Family composition was comparable to UK norms, with $70 \%$ of families in the study living in 2-parent households (77\% in a recent UK epidemiological survey Social trends, 2009).

Families were assessed at recruitment then an average of 16 months later ( $S D=2.69$, range 11 to 27 ). Retention rate at follow-up was $96 \%(n=323)$ with full interview data available on $86 \%$ of parents $(n=290)$ and $82 \%$ of children $(\mathrm{n}=277)$. An additional 2 families were excluded as the affected parent had been re-diagnosed as suffering from bipolar disorder between assessments. This resulted in a final sample of 288 parents and 275 children available for analyses. At the time of the second assessment, all of the children were living primarily with the affected parent save one, who had moved out 3 months prior but had remained in frequent contact.

\subsection{Procedure}

The Multi-centre Research Ethics Committee for Wales reviewed and approved the study protocol. Prior to participation, parents and children were provided with a description of the study and written informed consent or assent was then obtained from all participants as appropriate.

Data were collected from parents and children via semistructured diagnostic interviews. These were completed with the parent and child independently of each other, in separate rooms in most instances and in $99 \%$ of cases by separate researchers. Assessments were conducted in the family home (99\%) or at the university hospital (1\%) by teams of two trained interviewers, all of whom were psychology graduates and were supervised weekly by a team of clinical child and adolescent (AT, RP) and adult (DS) psychiatrists. Interviewers were aware that all parents had experienced recurrent depression but were blind to parent's and children's current psychiatric status at the time of each assessment.

\subsection{Assessments}

\subsubsection{Parent depression diagnosis and prior depression episodes}

The index parents' current psychiatric state was assessed using the Schedules for Clinical Assessment in Neuropsychiatry (Wing et al., 1990). This interview was used to assess whether an episode of DSM-IV depression had occurred over the previous month. The interviewer agreement for coding DSM-IV parental depression diagnosis was perfect (kappa $=1)$. A timeline of the affected parent's previous depressive episodes was compiled using a life history calendar approach which is a method of collecting information retrospectively where life events are used as markers to aid recall (Belli, 1998; Caspi et al., 1996; Freedman et al., 1988). Parents were required to provide details about previous episodes of depression (including episode timing, duration and treatment) and identify their worst two depressive episodes. The timeline data was used to provide information about age of depression onset (dichotomised according to previous research into $\leq 20$ versus 21 years or older (Weissman et al., 1984), episode duration (an average of the worst two reported episodes), whether episodes had been frequent (classified as 4 or greater) and any periods of hospitalisation for depression. Information about depression during pregnancy and the postnatal period (up to 1 year after birth) with the index child was also collected from the mothers in the sample.

\subsubsection{Severity, impairment and family history}

Information regarding severity and associated level of impairment was ascertained by assessing the two worst depressive episodes in detail. Level of impairment was assessed using the Global Assessment of Functioning (GAF) scale (American Psychiatric Association, [DSM-IV], 1994) which is a numerical scale (range 0-100) used to rate levels of social, occupational and psychological functioning with lower scores indicating greater impairment. A severe episode was defined as an episode involving either severe impairment $(\mathrm{GAF} \leq 30)$ or hospitalisation due to depression in accordance with previous criteria (Hammen and Brennan, 2003). Family history of depression was also assessed at baseline by asking parents about all first degree relatives of the child (siblings, parents and grandparents). A count based method was then used to calculate the number of family members affected (Milne et al., 2008).

\subsubsection{Recent episode of parental depression}

This was defined using data from the SCAN interview at recruitment and at follow-up. Details of any depressive episodes experienced since the first assessment were retrospectively recalled and documented. Based on this information, parents were categorised according to whether they had experienced a recent episode of depression - defined as meeting DSM-IV criteria for depression at either the baseline (assessing the last month) or follow-up assessments (assessing the last month) or having reported a depressive episode in between. One hundred and sixty-six (57.8\%) of the index parents who took part in the follow-up interview (154/268 mothers; $12 / 20$ fathers) had experienced a recent episode of depression. Of these, sixty-three (22\%) had a current diagnosis at baseline, fifty-two (18.2\%) at follow-up and 158 (55.1\%) reported an episode between the assessments. Recent parental depression was used as the primary predictor of child outcomes.

\subsubsection{Child outcomes}

The child outcome measures were analysed from data obtained at the follow-up interview (child age range 1018 years, mean 13.8 years). Child diagnosis and depression symptoms were assessed using the parent and child versions of the Child and Adolescent Psychiatric Assessment [CAPA (Angold and Costello, 2000)]. This is a semi-structured diagnostic interview which was used to assess depressive disorders, anxiety disorders, oppositional defiant disorder, conduct disorder, ADHD (parent only), bipolar disorder, eating disorders, and psychosis based on symptoms and impairment present in children and adolescents during the preceding 3 months.

Parent and child rated diagnoses were combined (using an either/or approach) to provide an overall DSM-IV diagnosis as used previously (Angold and Costello, 1995), All cases meeting criteria for diagnosis and all those with sub-threshold symptoms were reviewed by two child psychiatrists and 
diagnoses were agreed by clinical consensus. Clinician agreement was perfect for both parent-reported and childreported DSM-IV psychiatric disorder at follow-up (presence/absence). There was only one instance where clinicians differed regarding the specific diagnoses given (one giving a diagnosis of adjustment disorder and the other major depressive disorder).

The agreement between parent and offspring reports for child disorder (presence/absence) at follow-up was low (kappa $=0.120, \mathrm{p}<0.05$ ). This is consistent with other studies which have generally found low to moderate agreement between informants when assessing child psychiatric disorder (Cantwell et al., 1997) and highlights the need to obtain data from multiple informants whenever possible.

The total number of DSM-IV major depression symptoms was also computed from the child CAPA (maximum of 9). The average agreement between interviewers for child-rated CAPA depression symptoms was excellent (mean kappa $=0.90$ ).

\section{Statistical analysis}

Two child outcomes were analysed: Diagnosis of any DSM-IV psychiatric disorder and number of child-rated depression symptoms. The outcome diagnoses included all mood disorders, anxiety disorders, disruptive disorders (ODD and CD) and other disorders (eating disorders and adjustment disorders). In accordance with previous research on the offspring of depressed parents, specific phobias were not included as outcomes (Hammen and Brennan, 2003). Additionally, as ADHD is not assessed by the child CAPA, this outcome was also not included in the primary analyses, although further analyses including parent reports of ADHD were also conducted and similar results were found (available on request). A disorder was considered present if reported by either the parent or the child.

The distribution of depression symptoms reported by the child was positively skewed and therefore transformed prior to analysis using a natural log transformation. Logistic and linear regressions were used to analyse disorder and symptom score outcomes respectively. Analysis of variance and chi-square statistics were used to compare parents with and without recent depression on a number of different clinical depression characteristics. These included depression during pregnancy, postnatal depression (with the index child), average episode duration, frequent episodes, severe episodes, early age of onset, and family history of depression. Those variables that were associated with both a recent episode of parental depression and child outcome (psychiatric disorder or depressive symptoms) were included in further multivariate analyses. Age and sex of child at follow-up, and their interaction were included as covariates.

\section{Results}

Table 1 presents clinical information regarding the index parent's history of depression and the diagnoses in the children at the follow-up assessment. Rates of any DSM-IV disorder (parent and child disorder combined) were similar for boys and girls ( $28.7 \%$ vs. $27.3 \%, \mathrm{OR}=0.934, \mathrm{CI}=0.55,1.58$, $\mathrm{p}=0.800$ ), however girls experienced significantly higher rates of depressive disorders than boys (10.5\% vs. 3.5\%, $\mathrm{OR}=3.24, \mathrm{CI}=1.07,9.85, \mathrm{p}=0.038$ ). Rates of disorder did not differ significantly between older ( $\geq 14$ years) and younger children $(30.7 \%$ vs. $24.8 \%, \mathrm{OR}=1.34, \mathrm{CI}=0.80,2.26$, $\mathrm{p}=0.270$ ). In line with previous studies of children of depressed parents (Beardslee et al., 1998; Goodman and Gotlib, 1999; Weissman et al., 2006) this study found elevated rates of disorder in offspring when compared with normative data from a recent UK epidemiological survey of children aged 1115 years (Green et al., 2004) . Specifically there were higher rates of overall $\left(27.9 \%\right.$ vs. $\left.11.7 \% X^{2}=61.5, p=<0.01\right)$, depressive ( $7.7 \%$ vs. $\left.2.6 \% X^{2}=23.6, p=<0.01\right)$, anxiety $(13.2 \%$ vs. $4.4 \% X^{2}=43.0, \mathrm{p}=<0.01$ ), disruptive behaviour disorders (conduct disorder and oppositional defiant disorder; $10.1 \%$ vs. $\left.7.0 \% X^{2}=3.8, p=0.05\right)$ and ADHD (6.6\% vs. $1.5 \%$ $X^{2}=36.9, \mathrm{p}=<0.01$ ).

\section{Recent parental depression as a predictor of child outcomes}

\subsection{Child diagnoses}

A significant association was found between recent parental depression and child disorder (parent and child combined, Table 2). Children of parents who had recently experienced an episode of depression were significantly more likely to have a psychiatric disorder than children who had not been recently exposed $(\mathrm{OR}=2.00, \mathrm{CI}=1.12,3.56, \mathrm{p}=0.019)$.

When analyses excluded children with a psychiatric disorder at baseline, those children who had been recently exposed to a parental depressive episode also showed a higher rate of newonset psychiatric disorder compared to children who had not been recently exposed, although the association was not significant $(21.4 \%$ when recent parental depression versus $14.3 \%$ when no recent depression, $\mathrm{OR}=1.70, \mathrm{CI}=0.84,3.42, \mathrm{p}=0.140$. Child disorder at baseline is described in Supplementary Table 1).

There was no evidence of cross-sectional association between current parental diagnosis of DSM-IV depression (assessed by the SCAN over the preceding month) and child disorder at baseline $(\mathrm{OR}=1.59, \mathrm{CI}=0.87,2.90, \mathrm{p}=0.135)$, however a significant cross-sectional association was found between current parental depression and child psychiatric disorder at follow-up $(\mathrm{OR}=1.60, \mathrm{CI}=1.15,2.22, \mathrm{p}=0.006)$.

\subsection{Child-rated depression symptom scores}

An interaction was found between child age and sex at follow-up such that older girls were found to report more depressive symptoms $(\beta=0.086, p=0.019)$. This interaction term was therefore included in all subsequent analyses. Linear regression analysis revealed a significant association between recent parental depression and child-rated depression symptoms $(\beta=0.17, C I=0.03,0.31, p=0.017)$. Children who had recently been exposed to a parental depressive episode reported significantly more depressive symptoms (untransformed mean $=1.43, \mathrm{SD}=1.73$ ) than children who had not been recently exposed (untransformed mean $=1.00, \mathrm{SD}=1.38$ ). There was no evidence of cross-sectional association between current parental diagnosis of DSM-IV depression (assessed by the SCAN over the preceding month) at each time point and child-rated 
Table 1

Parent and child clinical characteristics at follow-up ${ }^{\mathrm{a}}$.

\begin{tabular}{|c|c|}
\hline Parent depression characteristics $(n=288)$ & Sample mean (SD) or \% (n) \\
\hline Depression during pregnancy with index child, \% (n) & $10.2(27 / 264)$ \\
\hline Postnatal depression with index child (within 1 year), \% (n) & $42.4(112 / 264)$ \\
\hline Average episode duration (months), mean (SD) & $16.6(22.3)$ \\
\hline 4 or more depressive episodes, \% (n) & $38.4(108 / 281)$ \\
\hline $\begin{array}{l}\text { Severe depressive episode: severe impairment }(\mathrm{GAF} \leq 30) \text { or } \\
\text { hospitalised for depression, \% (n) }\end{array}$ & $27.9(79 / 283)$ \\
\hline $\begin{array}{l}\text { Family history of depression - number of affected first degree } \\
\text { relatives of the child, mean }(S D)^{a}\end{array}$ & $1.5(0.7)$ \\
\hline 1 family member, \%, (n) & $59.4(171 / 288)$ \\
\hline 2 family members, \% (n) & $30.9(89 / 288)$ \\
\hline 3 or more family members, $\%$ (n) & $9.6(28 / 288)$ \\
\hline Early age of depression onset, $\leq 20, \%$ (n) & $27.0(76 / 282)$ \\
\hline Recent episode of depression, \% (n) & $57.8(166 / 287)$ \\
\hline DSM-IV depression at baseline, \% (n) & $22.0(63 / 287)$ \\
\hline DSM-IV depression at follow-up, \% (n) & $18.2(52 / 285)$ \\
\hline Depressive episode in between assessments, \% (n) & $55.1(158 / 287)$ \\
\hline Child diagnoses at follow-up ${ }^{\mathrm{b}}$ & $\%(n)$ \\
\hline Any child DSM-IV disorder (not including specific phobias) & $27.9(80)$ \\
\hline Depressive disorders & $7.7(22)$ \\
\hline Anxiety disorders & $13.2(38)$ \\
\hline Disruptive behaviour disorders & $10.1(29)$ \\
\hline ADHD & $6.6(19)$ \\
\hline Other disorders & $3.1(9)$ \\
\hline Specific phobias & $7.3(21)$ \\
\hline
\end{tabular}

a Numbers vary due to missing data.

b Depressive disorders include major depressive disorder, dysthymia and depression not otherwise specified. Anxiety disorders include generalised anxiety disorder, separation anxiety, social phobia, panic disorder, agoraphobia and obsessional compulsive disorder. Disruptive behaviour disorders includes oppositional defiant disorder, conduct disorder and disruptive behaviour not otherwise specified. Other disorders includes bipolar spectrum disorders (3), cyclothymia (2), eating disorders (3) and adjustment disorders (1).

depression symptoms (baseline $\beta=0.11, \mathrm{CI}=-0.04,0.26$, $\mathrm{p}=0.153$; follow-up $\beta=0.09, \mathrm{CI}=0.00,0.18, \mathrm{p}=0.051$ ).

\section{Other features of parent depression associated with child outcomes}

Presence of a previous severe depressive episode in the parent was associated with both child disorder $(\mathrm{OR}=1.81$, $\mathrm{CI}=1.01,3.24, \mathrm{p}=0.047)$ and child depression symptoms $(\beta=0.19 \mathrm{CI}=0.04, \quad 0.35, \quad \mathrm{p}=0.015)$. Family history $(\beta=0.10 \mathrm{CI}=0.01,0.19, \mathrm{p}=0.038)$ was also associated with number of child depression symptoms (Table 3 ). No associations were found between any of the other features of parental depression examined (postnatal depression, depression during pregnancy, average episode duration, frequent episodes or early age of depression onset) and either child outcome.

\section{Is recent parental depression associated with child out- comes when prior depression features are taken into consideration?}

Of the parent depression features associated with child outcomes, only prior depression severity was also associated with

Table 2

Rates of child DSM-IV psychiatric disorder according to recent parental depression.

\begin{tabular}{llll}
\hline DSM-IV psychiatric disorder ${ }^{\mathrm{a}}$ & \multicolumn{3}{l}{ Recent parental depressive episode,\% (n) } \\
& Yes & No & $\mathrm{n}=121$ \\
\hline Parent and child combined diagnosis & $\mathrm{n}=166$ & $18.2 \%(22)$ & $2.00(1.12,3.56)$ \\
Any DSM-IV disorder & $30.3 \%(50)$ & $5.8 \%(7)$ & $1.58(0.61,4.05)$ \\
Any depressive disorder & $9.1 \%(15)$ & $9.9 \%(12)$ & $1.71(0.82,3.56)$ \\
Any anxiety disorder & $15.8 \%(26)$ & $5.8 \%(7)$ & 0.019 \\
Any disruptive disorder & $13.3 \%(22)$ & 0.345 & $2.59(1.06,6.30)$ \\
\hline
\end{tabular}

Analyses adjusted for child age, sex and their interaction measured at follow-up.

a Any DSM-IV disorder includes all assessed DSM-IV disorders apart from ADHD and specific phobias. Depressive disorders include major depressive disorder, dysthymia and depression not otherwise specified. Anxiety disorders include generalised anxiety disorder, separation anxiety, social phobia, panic disorder, agoraphobia and obsessional compulsive disorder. Disruptive behaviour disorder includes oppositional defiant disorder, conduct disorder and disruptive behaviour not otherwise specified. 
Table 3

Association between clinical features of parental depression and child outcome.

\begin{tabular}{|c|c|c|c|c|c|c|}
\hline \multirow[t]{2}{*}{ Parent depression characteristics ${ }^{a}$} & \multicolumn{4}{|c|}{$\begin{array}{l}\text { Child disorder } \\
\text { (parent and child combined ratings) } \\
\%(\mathrm{n}) \text { or mean }(\mathrm{SD})\end{array}$} & \multicolumn{2}{|c|}{$\begin{array}{l}\text { Child-rated and depression } \\
\text { symptoms }\end{array}$} \\
\hline & Yes $(n=72)$ & No $(n=215)_{-}$ & $\begin{array}{l}\text { OR } \\
(95 \% \mathrm{CI})\end{array}$ & $\mathrm{p}$ value & $\begin{array}{l}\beta \text { value } \\
(95 \% \mathrm{CI})\end{array}$ & $\mathrm{p}$ value \\
\hline $\begin{array}{l}\text { Depression during pregnancy with index child, } \\
\% \text { (n) }\end{array}$ & $\begin{array}{l}11.9 \\
(8)\end{array}$ & $\begin{array}{r}9.7 \\
(19)\end{array}$ & $\begin{array}{l}1.25 \\
(0.51,3.10)\end{array}$ & 0.509 & $\begin{array}{l}-0.037 \\
(-0.27,0.20)\end{array}$ & 0.754 \\
\hline $\begin{array}{l}\text { Postnatal depression with index (within } 1 \text { year), } \\
\%(n)\end{array}$ & $\begin{array}{l}47.8 \\
(32)\end{array}$ & $\begin{array}{l}40.8 \\
(80)\end{array}$ & $\begin{array}{l}1.52 \\
(0.84,2.75)\end{array}$ & 0.163 & $\begin{array}{l}0.066 \\
(-0.08,0.21)\end{array}$ & 0.386 \\
\hline Average episode duration, mean (SD) months & $\begin{array}{l}18.6 \\
(21.8)\end{array}$ & $\begin{array}{l}15.9 \\
(22.6)\end{array}$ & $\begin{array}{l}1.01 \\
(1.00,1.02)\end{array}$ & 0.218 & $\begin{array}{l}-0.001 \\
(-0.01,0.00)\end{array}$ & 0.411 \\
\hline 4 or more episodes \% (n) & $\begin{array}{l}42.9 \\
(30)\end{array}$ & $\begin{array}{l}36.7 \\
(77)\end{array}$ & $\begin{array}{l}1.41 \\
(0.80,2.47)\end{array}$ & 0.236 & $\begin{array}{c}0.124 \\
(-0.02,0.27)\end{array}$ & 0.090 \\
\hline $\begin{array}{l}\text { Severe depressive episode: severe impairment } \\
\quad(G A F<30) \text { or hospitalised for depression, \% (n) }\end{array}$ & $\begin{array}{l}38.0 \\
(27)\end{array}$ & $\begin{array}{l}24.6 \\
(52)\end{array}$ & $\begin{array}{l}1.81 \\
(1.01,3.24)\end{array}$ & 0.047 & $\begin{array}{c}0.193 \\
(0.04,0.35)\end{array}$ & 0.015 \\
\hline $\begin{array}{l}\text { Family history of depression (number of } 1 \text { st } \\
\text { degree family members) mean (SD) }\end{array}$ & $\begin{array}{c}1.6 \\
(0.78)\end{array}$ & $\begin{array}{c}1.5 \\
(0.73)\end{array}$ & $\begin{array}{l}1.17 \\
(0.82,1.66)\end{array}$ & 0.400 & $\begin{array}{c}0.100 \\
(0.01,0.19)\end{array}$ & 0.038 \\
\hline Early age of depression onset, <20, \% (n) & $\begin{array}{l}30.6 \\
(22)\end{array}$ & $\begin{array}{l}25.4 \\
(53)\end{array}$ & $\begin{array}{l}1.26 \\
(0.69,2.31)\end{array}$ & 0.446 & $\begin{array}{c}0.089 \\
(-0.07,0.25)\end{array}$ & 0.271 \\
\hline
\end{tabular}

Analyses adjusted for child age, sex and their interaction measured at follow-up.

a Numbers vary due to missing data.

recent parental depression (Table 4). Multiple regression analyses were therefore performed to assess the independent contributions of these two variables in predicting child outcomes (Table 5). Age and sex of child at follow-up, and their interaction were included as covariates.

\subsection{Child diagnoses}

In the multivariate analysis, when both severity and recent parental depression were included as predictors of child disorder, a significant association was found for recent depression. Prior depression severity was found to be marginally associated with child disorder. Further analyses showed no statistically significant interaction between recent depression and past severity $(\mathrm{OR}=0.90, \mathrm{CI}=0.25,3.21$, $\mathrm{P}=0.871$ ), suggesting an additive risk for child disorder (Fig. 1, 16.0\% if no recent depressive episode and no severe episode, 38.5\% when both recent depressive episode and severe episode). Results were similar when only mothers were included in the analyses (available on request).

\subsection{Child-rated depression symptom scores}

In the multivariate analyses, a significant association was found for both predictors, suggesting that both presence of a severe depressive episode and recent parental depression independently predict child depression symptoms (Table 5). Again there was no significant interaction between severity and recent depression $(\beta=-0.01, \quad C I=-0.33,0.32$, $\mathrm{p}=0.967)$, suggesting an additive risk also for child depression symptoms (see Supplementary Fig. 2, available online). Results were similar when only mothers were included in the analyses (available on request).

\section{Discussion}

Parental depression is one of the best established risk factors for offspring psychopathology with studies repeatedly showing higher rates of psychiatric disorder in the children of depressed parents compared with non-depressed controls (Beardslee et al., 1998; Goodman and Gotlib, 1999; Weissman et al., 2006). Consistent with this previous

Table 4

Association between parental depression features and recent parental episode.

\begin{tabular}{|c|c|c|c|}
\hline \multirow[t]{2}{*}{ Parent depression characteristics ${ }^{a}$} & \multicolumn{2}{|c|}{$\begin{array}{l}\text { Recent episode of parental depression \% (n) } \\
\text { or mean (SD) }\end{array}$} & \multirow[t]{2}{*}{$\begin{array}{l}\mathrm{p} \\
\text { value }\end{array}$} \\
\hline & Yes & No & \\
\hline Depression during pregnancy with index child, \% (n) & $13.8(23)$ & $6.2(7)$ & 0.047 \\
\hline Postnatal depression with index (within 1 year), \% (n) & $47.3(79)$ & $36.6(41)$ & 0.077 \\
\hline Average episode duration (months), mean (SD) & $20.0(29.5)$ & $12.4(10.5)$ & 0.007 \\
\hline 4 or more depressive episodes, \% (n) & $41.8(74)$ & $35.0(42)$ & 0.238 \\
\hline $\begin{array}{l}\text { Severe depressive episode by wave } 2 \\
\quad(\mathrm{GAF}<30 \text {, hospitalised or serious suicide attempt), \% (n) }\end{array}$ & 34.7 (59) & $22.3(27)$ & 0.022 \\
\hline $\begin{array}{l}\text { Family history of depression - number of family } \\
\text { members, mean (SD) }\end{array}$ & $1.59(0.77)$ & $1.46(0.68)$ & 0.142 \\
\hline Early age of depression onset, $<20, \%$ (n) & $30.7(55)$ & $20.3(24)$ & 0.047 \\
\hline
\end{tabular}

Analyses were conducted using analysis of variance/chi-square.

a Numbers vary due to missing data. 
Table 5

Univariate and multivariate analyses predicting child outcomes.

\begin{tabular}{|c|c|c|c|c|c|c|}
\hline \multirow[b]{2}{*}{$\begin{array}{l}\text { DSM-IV psychiatric disorder } \\
\text { Parent and child combined reports }\end{array}$} & \multicolumn{3}{|l|}{ Univariate analyses } & \multicolumn{3}{|c|}{ Multivariate analyses } \\
\hline & OR $(95 \% \mathrm{CI})$ & P value & $\mathrm{R}^{2}$ & OR $(95 \% \mathrm{CI})$ & P value & $\mathrm{R}^{2}$ \\
\hline Recent parental depressive episode & $2.00(1.12,3.56)$ & 0.019 & 0.048 & $1.93(1.073 .47)$ & 0.029 & 0.062 \\
\hline Severe depression history & $1.81(1.01,3.24)$ & 0.047 & 0.045 & $1.67(0.92,3.02)$ & 0.092 & \\
\hline $\begin{array}{l}\text { Depression symptom score } \\
\text { Child-rated }\end{array}$ & $\beta$ Value $(95 \% \mathrm{CI})$ & P value & $\mathrm{R}^{2}$ & $\beta$ Value $(95 \% \mathrm{CI})$ & P value & $\mathrm{R}^{2}$ \\
\hline Recent parental depressive episode & $0.168(0.03,0.31)$ & 0.017 & 0.088 & $0.149(0.01,0.29)$ & 0.036 & 0.107 \\
\hline Severe depression history & $0.193(0.04,0.35)$ & 0.015 & 0.096 & $0.169(0.01,0.32)$ & 0.033 & \\
\hline
\end{tabular}

Analyses adjusted for child age, sex and their interaction measured at follow-up.

research, high rates of psychopathology were found in the children in this sample, with over a quarter meeting criteria for a DSM-IV psychiatric disorder at follow-up. This is more than double the rate reported in a recent UK epidemiological survey of children aged 11-15 years (Green et al., 2004) and confirms the expectation that offspring of depressed parents are a high risk group.

Within this high risk sample, features of parents' depression further indexed children's risk for psychopathology. Offspring whose parents had experienced a recent depressive episode reported significantly more child-rated depression symptoms and the odds of child psychiatric disorder were doubled $(\mathrm{OR}=2.00,30 \%$ vs. $18 \%$ ) relative to children who had not recently been exposed.

The direct evidence on the importance of recent parental depressive episodes as a risk indicator to children is consistent with other observational and treatment studies (Gunlicks and Weissman, 2008). Genetically informative studies suggest that the association between concurrent parent depression and child depression appears to have a strong environmental explanation along with some evidence of inherited liability (Harold et al., 2010; Silberg et al., 2010; Tully et al., 2008), and some but not all treatment studies have found reductions

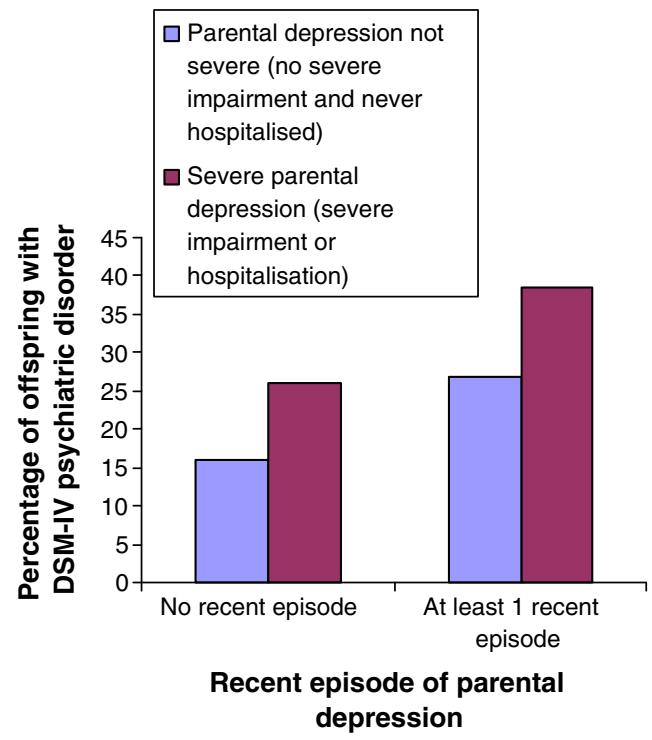

Fig. 1. Percentage of children with a disorder according to both past episode severity and recent parental depression. in overall levels of psychiatric disorder (but not depression specifically) in children of mothers whose depression remits after treatment (Gunlicks and Weissman, 2008).

Although our study design does not allow a test of causality, we were able to examine whether features of parent depression other than the presence of a recent episode were associated with higher offspring risk. All of the index parents in this sample had suffered from recurrent depression at baseline, however, those who experienced episode recurrence over the assessment period appear to have suffered from an overall worse course of affective illness (including a greater likelihood of having an early age of onset $(\leq 20)$, longer episode duration, a greater likelihood of depression during pregnancy and postnatally, and a greater likelihood of having had severe episodes). It is therefore possible that recent parental depression is merely acting as a marker for greater clinical severity, and this could potentially provide a better explanation for the association with child psychopathology.

In our study, presence of a severe parental depressive episode was found to be associated with both child DSM-IV disorder and number of child-rated depression symptoms. However, when examined together, a recent episode of parent depression continued to predict both child disorder and child depression symptoms. Prior episode severity also continued to predict child depression symptoms and was marginally predictive of offspring DSM-IV disorder, suggesting that both these variables may be useful markers of risk in children. For children's depression symptoms, family history (number of 1st degree relatives with depression) was also significantly associated, and not confounded with recent parent depression, suggesting that it might be an additional useful indicator of risk for depression in children. Our findings contrast with previous studies that have found associations between early age of parental depression onset and offspring depression (Klein et al., 2005; Weissman et al., 1984). This may be because there were insufficient numbers of parents with early age of onset to detect an association, or it is possible that age of onset may be a marker of risk for child depressive disorder specifically.

Consistent with the findings from the present study, the only other study to examine multiple features of parent depression (timing, chronicity and severity but not recent depression; (Hammen and Brennan, 2003) also found past depression severity in parents to be a significant predictor of childhood depressive disorders. Overall this study extends previous findings by suggesting that recent parental depression remains a significant predictor of both child depression symptoms and child 
DSM-IV psychiatric disorder when correlated features of parental depression such as severity are considered. Possible shared rater effects were also ruled out as associations with recent parental depression were confirmed using children's own reports of their depression symptoms.

The reasons for this increased risk in the offspring of depressed parents likely involve a complex interplay of genetic and environmental factors (Lau and Eley, 2010; Tully et al., 2008) and to date many mechanisms have been proposed to explain the cross-generational transmission of depression. These could include impaired parenting, difficult parent-child relationships, increased conflict, high levels of family stress, dysfunctional neuroregulatory mechanisms, and exposure to negative parental cognitions, behaviour and affect as well as a genetic predisposition (Cummings et al., 2005; Goodman and Gotlib, 1999; Herr et al., 2007; Lovejoy et al., 2000).

\subsection{Implications}

It is well established that children of depressed parents are at risk for psychopathology (Weissman et al., 2006). Our findings extend this by suggesting that certain features of parent depression, specifically recent episodes and more severe depression (including hospitalisation and high levels of impairment) can be useful markers of risk in offspring. Although causal relationships could not be established here, identifying risk markers is also important. Clinicians should be vigilant of these in order to identify children who may warrant monitoring regarding the possibility of psychopathology and who might especially benefit from prevention and early intervention strategies.

Monitoring children who exhibit depression symptoms is crucial as they may be indicative of future problems, particularly when accompanied by psychosocial impairment (Angold et al., 1999; Fergusson et al., 2005; Lewinsohn et al., 2000; Pickles et al., 2001; Pine et al., 1999). Intervening at this stage could potentially prevent subthreshold symptoms from escalating into full depressive disorder, which is likely to have serious adverse consequences for future development.

Effective treatment of depression in parents remains a clinical priority because of the substantial associated suffering and morbidity. However, the results of this study suggest that recent parent depressive episodes may also index a more severe clinical course. The implication of this is that simply treating current parent depression may not be sufficient to forestall the onset of depressive symptoms or psychiatric disorder in offspring.

\subsection{Limitations}

Several limitations of this study need to be noted; firstly many of the features of recurrent depression that were investigated (such as episode number, duration and timing) were reported retrospectively by the affected parent so there may have been inaccuracies. To minimise this, a life history calendar approach was adopted when generating the depression timeline whereby major events were included as a way of aiding recall. Also, we did not assess lifetime suicidality in the parents which may be an additional indicator of depression severity.
Secondly, although child outcomes were assessed at 2 time points, these analyses focused only on outcomes measured at the follow-up assessment, thus the direction of association could not be established and possible child effects on parent depression symptoms can not be ruled out. This approach was adopted to allow for recent parental depression to be defined over a longer time period than 1 month, since cross-sectionally, current parental depression (occurring over the previous month) was not found to be associated with child psychopathology. This might have been because the numbers of parents with current depression were too few to detect associations with child psychopathology. Alternatively, it is possible that the time frame used to define current parent depression might be too short for any associated risk to children to be detected. A final explanation is that current and recent parental depression are simply risk markers for child psychopathology, with the latter serving as a better marker.

Thirdly, although rates of child psychiatric disorder are high compared to population norms, there was insufficient power to adequately investigate associations with individual psychiatric disorders. Limited power also prevented examination of potential differences according to child age and parent and child gender which previous research has suggested may be important moderators of risk in the intergenerational transmission of depression (Cortes et al., 2006; Davies and Windle, 1997; Fergusson et al., 1995; Jenkins and Curwen, 2008; Lewis et al., 2011). It should also be noted that the children in this sample were aged 10-18 years at the time of assessment and so have yet to pass fully through the optimal age of risk for depression.

Finally, given that clinical features of depression such as timing, chronicity and severity are inextricably linked, this study was not able to fully disentangle the risk to children uniquely associated with recent parental depression. However, disaggregating these features is a considerable problem for the majority of study designs, and therefore, empirically establishing a causal relationship between specific clinical variants of parental depression and child outcomes is likely to prove extremely difficult. Additionally, it is also possible that there are other unmeasured and untested third variables which could be contributing to the association, including other co-occurring parental psychopathology (Kim-Cohen et al., 2005).

\subsection{Summary}

This study extended previous research by investigating associations between recent parental depression and offspring psychopathology in a community sample of recurrently depressed parents. Other depression factors were also considered. Recent parental depression was found to be significantly associated with both child psychiatric disorder and child-rated depression symptoms. Prior severity of parent depression was also associated with child depression symptoms. Furthermore these associations were also found using child ratings of their own psychopathology. These indicators of risk might be helpful where treatment resources are limited and when prevention and early intervention strategies for offspring of recurrently depressed parents need to be targeted towards those at greatest risk. 
Supplementary materials related to this article can be found online at doi:10.1016/j.jad.2011.09.002.

\section{Role of funding source}

Funding for this study was provided by the Sir Jules Thorn Medical Trust and the Waterloo Foundation; they had no further role in the study design, the collection, analysis and interpretation of data, the writing of the report, or in the decision to submit the paper for publication.

\section{Conflict of interest}

None of the authors have conflict of interest/financial disclosures, with the exception of Dr Daniel Smith who has received honoraria for speaking at educational meetings organised by AstraZeneca and Lilly.

\section{Acknowledgments}

Funding support: Sir Jules Thorn Medical Trust, Waterloo Foundation.

Thank you to: Michael, J. Owen, Ruth Sellers, Claire Delduca, Lynne Barry, Jennifer Hilgart, Eleni Kopsida, Olga Eyre, Sophie Thomas, Sophie Canton, Gemma Hammerton, Sophie Keates, Garret Coy, Rebecca Davis, Katie Lewis, Lucy Kift, Valerie Russell, Gemma Lewis.

\section{References}

American Psychiatric Association, 1994. Diagnostic and statistical manual of mental disorders, 4th ed. . Washington, DC.

Angold, A., Costello, E.J., 1995. A test-retest reliability study of child-reported psychiatric symptoms and diagnoses using the Child and Adolescent Psychiatric Assessment (CAPA-C). Psychological Medicine 25, 755-762.

Angold, A., Costello, E.J., 2000. The Child and Adolescent Psychiatric Assessment (CAPA). Journal of the American Academy of Child and Adolescent Psychiatry 39, 39-48.

Angold, A., Costello, E.J., Farmer, E.M., Burns, B.J., Erkanli, A., 1999. Impaired but undiagnosed. Journal of the American Academy of Child and Adolescent Psychiatry 38, 129-137.

Beardslee, W.R., Versage, E.M., Gladstone, T.R., 1998. Children of affectively ill parents: a review of the past 10 years. Journal of the American Academy of Child and Adolescent Psychiatry 37, 1134-1141.

Belli, R.F., 1998. The structure of autobiographical memory and the event history calendar: potential improvements in the quality of retrospective reports in surveys. Memory 6, 383-406.

Birmaher, B., Ryan, N.D., Williamson, D.E., Brent, D.A., Kaufman, J., Dahl, R.E. Perel, J., Nelson, B., 1996. Childhood and adolescent depression: a review of the past 10 years. Part I. Journal of the American Academy of Child and Adolescent Psychiatry 35, 1427-1439.

Brand, S.R., Brennan, P.A., 2009. Impact of antenatal and postpartum maternal mental illness: how are the children? Clinical Obstetrics and Gynecology 52, 441-455.

Brennan, P.A., Hammen, C., Andersen, M.J., Bor, W., Najman, J.M., Williams, G.M., 2000. Chronicity, severity, and timing of maternal depressive symptoms: relationships with child outcomes at age 5 . Developmental Psychology 36, 759-766.

Cantwell, D.P., Lewinsohn, P.M., Rohde, P., Seeley, J.R., 1997. Correspondence between adolescent report and parent report of psychiatric diagnostic data. Journal of the American Academy of Child and Adolescent Psychiatry 36, 610-619.

Caspi, A., Moffitt, T.E., Thornton, A., Freedman, D., Amell, J.W., Harrington, H., Smeijers, J., Silva, P.A., 1996. The life history calendar: a research and clinical assessment method for collecting retrospective event-history data. International Journal of Methods in Psychiatric Research 6, 101-114.

Connell, A.M., Goodman, S.H., 2002. The association between psychopathology in fathers versus mothers and children's internalizing and externalizing behavior problems: a meta-analysis. Psychological Bulletin 128 746-773.

Cortes, R.C., Fleming, C.B., Catalano, R.F., Brown, E.C., 2006. Gender differences in the association between maternal depressed mood and child depressive phenomena from grade 3 through grade 10. Journal of Youth and Adolescence $35,810-821$.

Cummings, E.M., Keller, P.S., Davies, P.T., 2005. Towards a family process model of maternal and paternal depressive symptoms: exploring multiple relations with child and family functioning. Journal of Child Psychology and Psychiatry, and Allied Disciplines 46, 479-489.

Davies, P.T., Windle, M., 1997. Gender-specific pathways between maternal depressive symptoms, family discord, and adolescent adjustment. Developmental Psychology 33, 657-668.
Fergusson, D.M., Horwood, L.J., Lynskey, M.T., 1995. Maternal depressive symptoms and depressive symptoms in adolescents. Journal of Child Psychology and Psychiatry, and Allied Disciplines 36, 1161-1178.

Fergusson, D.M., Horwood, L.J., Ridder, E.M., Beautrais, A.L., 2005. Subthreshold depression in adolescence and mental health outcomes in adulthood. Archives of General Psychiatry 62, 66-72.

Fombonne, E., Wostear, G., Cooper, V., Harrington, R., Rutter, M., 2001a. The Maudsley long-term follow-up of child and adolescent depression. 1. Psychiatric outcomes in adulthood. The British Journal of Psychiatry $179,210-217$.

Fombonne, E., Wostear, G., Cooper, V., Harrington, R., Rutter, M., 2001b. The Maudsley long-term follow-up of child and adolescent depression. 2. Suicidality, criminality and social dysfunction in adulthood. The British Journal of Psychiatry 179, 218-223.

Foster, C.E., Webster, M.C., Weissman, M.M., Pilowsky, D.J., Wickramaratne, P.J., Rush, A.J., Hughes, C.W., Garber, J., Malloy, E., Cerda, G., Kornstein, S.G., Alpert, J.E., Wisniewski, S.R., Trivedi, M.H., Fava, M., King, C.A., 2008. Course and severity of maternal depression: associations with family functioning and child adjustment. Journal of Youth and Adolescence $37,906-916$

Freedman, D., Thornton, A., Camburn, D., Alwin, D., Young-Demarco, L., 1988. The life history calendar: a technique for collecting retrospective data. Sociological Methodology 18, 37-68.

Goodman, S.H., Gotlib, I.H., 1999. Risk for psychopathology in the children of depressed mothers: a developmental model for understanding mechanisms of transmission. Psychology Review 106, 458-490.

Green, H., McGinnity, A., Meltzer, H., Ford, T., Goodman, R., 2004. Mental Health of Children and Young People in Great Britain. The Stationary Office, London.

Gunlicks, M.L., Weissman, M.M., 2008. Change in child psychopathology with improvement in parental depression: a systematic review. Journal of the American Academy of Child and Adolescent Psychiatry 47, 379-389.

Halligan, S.L., Murray, L., Martins, C., Cooper, P.J., 2007. Maternal depression and psychiatric outcomes in adolescent offspring: a 13-year longitudinal study. Journal of Affective Disorders 97, 145-154.

Hammen, C., Brennan, P.A., 2003. Severity, chronicity, and timing of maternal depression and risk for adolescent offspring diagnoses in a community sample. Archives of General Psychiatry 60, 253-258

Harold, G.T., Rice, F., Hay, D.F., Boivin, J., Van Den Bree, M., Thapar, A., 2010. Familial transmission of depression and antisocial behavior symptoms: disentangling the contribution of inherited and environmental factors and testing the mediating role of parenting. Psychological Medicine 1-11.

Harrington, R., Fudge, H., Rutter, M., Pickles, A., Hill, J., 1990. Adult outcomes of childhood and adolescent depression. I. Psychiatric status. Archives of General Psychiatry 47, 465-473.

Hay, D.F., Pawlby, S., Waters, C.S., Sharp, D., 2008. Antepartum and postpartum exposure to maternal depression: different effects on different adolescent outcomes. Journal of Child Psychology and Psychiatry, and Allied Disciplines 49, 1079-1088.

Herr, N.R., Hammen, C., Brennan, P.A., 2007. Current and past depression as predictors of family functioning: a comparison of men and women in a community sample. Journal of Family Psychology 21, 694-702.

Jenkins, J.M., Curwen, T., 2008. Change in adolescents' internalizing symptomatology as a function of sex and the timing of maternal depressive symptomatology. Journal of the American Academy of Child and Adolescent Psychiatry 47, 399-405.

Kim-Cohen, J., Moffitt, T.E., Taylor, A., Pawlby, S.J., Caspi, A., 2005. Maternal depression and children's antisocial behavior: nature and nurture effects. Archives of General Psychiatry 62, 173-181.

Klein, D.N., Lewinsohn, P.M., Rohde, P., Seeley, J.R., Olino, T.M., 2005. Psychopathology in the adolescent and young adult offspring of a community sample of mothers and fathers with major depression. Psychological Medicine 35, 353-365.

Lau, J.Y., Eley, T.C., 2010. The genetics of mood disorders. Annual Review of Clinical Psychology 6, 313-337.

Lewinsohn, P.M., Solomon, A., Seeley, J.R., Zeiss, A., 2000. Clinical implications of "subthreshold" depressive symptoms. Journal of Abnormal Psychology 109, 345-351.

Lewis, G., Rice, F., Harold, G.T., Collishaw, S., Thapar, A., 2011. Investigating environmental links between parent depression and child depressive/anxiety symptoms using an assisted conception design. Journal of the American Academy of Child and Adolescent Psychiatry 50 (451-459), e1.

Lovejoy, M.C., Graczyk, P.A., O'Hare, E., Neuman, G., 2000. Maternal depression and parenting behavior: a meta-analytic review. Clinical Psychology Review 20, 561-592.

Milne, B.J., Moffitt, T.E., Crump, R., Poulton, R., Rutter, M., Sears, M.R., Taylor, A., Caspi, A., 2008. How should we construct psychiatric family history scores? A comparison of alternative approaches from the Dunedin Family Health History Study. Psychological Medicine 38, 1793-1802. 
Murray, L., Sinclair, D., Cooper, P., Ducournau, P., Turner, P., Stein, A., 1999. The socioemotional development of 5-year-old children of postnatally depressed mothers. Journal of Child Psychology and Psychiatry, and Allied Disciplines 40, 1259-1271.

Murray, L., Arteche, A., Fearon, P., Halligan, S., Croudace, T., Cooper, P., 2010. The effects of maternal postnatal depression and child sex on academic performance at age 16 years: a developmental approach. Journal of Child Psychology and Psychiatry, and Allied Disciplines 51, 1150-1159.

Murray, L., Arteche, A., Fearon, P., Halligan, S., Goodyer, I., Cooper, P., 2011. Maternal postnatal depression and the development of depression in offspring up to 16 years of age. Journal of the American Academy of Child and Adolescent Psychiatry 50, 460-470.

Pickles, A., Rowe, R., Simonoff, E., Foley, D., Rutter, M., Silberg, J., 2001. Child psychiatric symptoms and psychosocial impairment: relationship and prognostic significance. The British Journal of Psychiatry 179, 230-235.

Pine, D.S., Cohen, P., Gurley, D., Brook, J., Ma, Y., 1998. The risk for earlyadulthood anxiety and depressive disorders in adolescents with anxiety and depressive disorders. Archives of General Psychiatry 55, 56-64.

Pine, D.S., Cohen, E., Cohen, P., Brook, J., 1999. Adolescent depressive symptoms as predictors of adult depression: moodiness or mood disorder? The American Journal of Psychiatry 156, 133-135.

Rao, U., Ryan, N.D., Birmaher, B., Dahl, R.E., Williamson, D.E., Kaufman, J., Rao, R., Nelson, B., 1995. Unipolar depression in adolescents: clinical outcome in adulthood. Journal of the American Academy of Child and Adolescent Psychiatry 34, 566-578.

Rice, F., Harold, G., Thapar, A., 2002. The genetic aetiology of childhood depression: a review. Journal of Child Psychology and Psychiatry, and Allied Disciplines 43, 65-79.
Rutter, M., Kim-Cohen, J., Maughan, B., 2006. Continuities and discontinuities in psychopathology between childhood and adult life. Journal of Child Psychology and Psychiatry, and Allied Disciplines 47, 276-295.

Silberg, J.L., Maes, H., Eaves, L.J., 2010. Genetic and environmental influences on the transmission of parental depression to children's depression and conduct disturbance: an extended Children of Twins study. Journal of Child Psychology and Psychiatry, and Allied Disciplines 51, 734-744.

Sutter-Dallay, A.L., Murray, L., Dequae-Merchadou, L., Glatigny-Dallay, E., Bourgeois, M.L., Verdoux, H., 2010. A prospective longitudinal study of the impact of early postnatal vs. chronic maternal depressive symptoms on child development. European Psychiatry doi:org/10.1016/j.eurpsy.2010.05.004.

Tully, E.C., Iacono, W.G., McGue, M., 2008. An adoption study of parental depression as an environmental liability for adolescent depression and childhood disruptive disorders. The American Journal of Psychiatry 165, 1148-1154.

Weissman, M.M., Wickramaratne, P., Merikangas, K.R., Leckman, J.F., Prusoff, B.A., Caruso, K.A., Kidd, K.K., Gammon, G.D., 1984. Onset of major depression in early adulthood. Increased familial loading and specificity. Archives of General Psychiatry 41, 1136-1143.

Weissman, M.M., Wolk, S., Goldstein, R.B., Moreau, D., Adams, P., Greenwald, S., Klier, C.M., Ryan, N.D., Dahl, R.E., Wickramaratne, P., 1999. Depressed adolescents grown up. JAMA 281, 1707-1713.

Weissman, M.M., Wickramaratne, P., Nomura, Y., Warner, V., Pilowsky, D., Verdeli, H., 2006. Offspring of depressed parents: 20 years later. The American Journal of Psychiatry 163, 1001-1008.

Wing, J.K., Babor, T., Brugha, T., Burke, J., Cooper, J.E., Giel, R., Jablenski, A., Regier, D., Sartorius, N., 1990. SCAN. Schedules for Clinical Assessment in Neuropsychiatry. Archives of General Psychiatry 47, 589-593. 